\title{
Degradation of esfenvalerate in illuminated water-sediment system
}

\author{
Rika KodaKa,* Terumi Sugano and Toshiyuki Katagi \\ Environmental Health Science Laboratory, Sumitomo Chemical Co., Ltd., \\ 4-2-1, Takatsukasa, Takarazuka, Hyogo 665-8555, Japan
}

(Received June 27, 2008; Accepted September 26, 2008)

\begin{abstract}
The aerobic aquatic soil metabolism of esfenvalerate [(2S, $\alpha S)$ - $\alpha$-cyano-3-phenoxybenzyl 2-(4-chlorophenyl)-3methylbutyrate] was examined in two Japanese pond water-sediment systems in relation to the effects of illumination and formulation on degradation profiles. Esfenvalerate was rapidly partitioned from the water phase to the bottom sediments with dissipation half-lives of less than 1 day and either the application of formulation or illumination slightly accelerated the partition. The main degradate of esfenvalerate was 3-phenoxybenzoic acid via ester cleavage both under dark and light conditions. The epimerization at the $\alpha$-cyanobenzyl carbon significantly proceeded to form the corresponding $[2 S, \alpha R]$ isomer in both water and sediment. The possible degradate via photo-induced decarboxylation was scarcely detected in the water phase of the illuminated water-sediment systems. (C) Pesticide Science Society of Japan
\end{abstract}

Keywords: biodegradation of pesticides, esfenvalerate, water-sediment system.

\section{Introduction}

Pesticide applied in the field partly enters an aquatic environment via spray-drift and run-off events and is considered to undergo either partition to suspended matters and bottom sediment or various degradation processes such as hydrolysis, photolysis and biotic metabolism. The hydrophobic nature of most pesticides results in their rapid partition to solid surfaces, which generally renders the importance of photochemical processes. In order to examine this environmental profile, a laboratory-scale water-sediment study under dark conditions as a model system is required for European registration of pesticides. ${ }^{1)}$ However, the photochemical process becomes more important for a photo-labile pesticide, especially in clear and shallow water bodies like a small stream, not only from its persistency but also in the ecotoxicological assessment of photo-products if formed to a greater extent. ${ }^{2)}$ Through several field-scale outdoor microcosm studies of pesticides, photolysis was found to play an important role especially near an air-water interface. ${ }^{3)}$ From this viewpoint, a water-sediment study under illumination is conditionally required for a photolabile pesticide with its direct photolysis half-life of a few days and formation of a photo-product above $10 \%$, but the

\footnotetext{
* To whom correspondence should be addressed.

Published online January 25, 2009

(C) Pesticide Science Society of Japan
}

practical study design is not still fixed. ${ }^{2)}$ Therefore, we have recently developed methodology for a water-sediment study under illumination with artificial sunlight using the plant growth regulator uniconazole-P [(S)-E-1-(4-chlorophenyl)4,4-dimethyl-2-(1,2,4-triazole-1-yl)-penten-3-ol] as a model compound. ${ }^{4}$

Pyrethroids are one of the most important and popular insecticides for agricultural use and many higher-tier outdoor microcosm and field mesocosm studies have been conducted to investigate their aquatic ecotoxicological impacts. ${ }^{5)}$ Their high hydrophobicity resulted in very rapid partition from water overlaid on bottom sediment. Although many outdoor studies have been conducted using radio-labeled pyrethroids, detailed information on their environmental fate is usually difficult to obtain due to the extremely lower concentration of degradates, except for a few cases. ${ }^{6-8)}$ Furthermore, these field studies are usually conducted using a commercial formulation in accordance with good agricultural practice and any effect of ingredients of the formulation, such as surfactant, on the environmental profiles of pesticide can be evaluated. In order to obtain information on the degradation of pyrethroid in a water column or bottom sediment, a model water-sediment system under illumination is considered very useful. Although the study is usually conducted using an active ingredient but not the corresponding formulation, Bromilow et al. ${ }^{9)}$ have recently reported the insignificant effect of the formulation on the distribution of eight pesticides, including perme- 


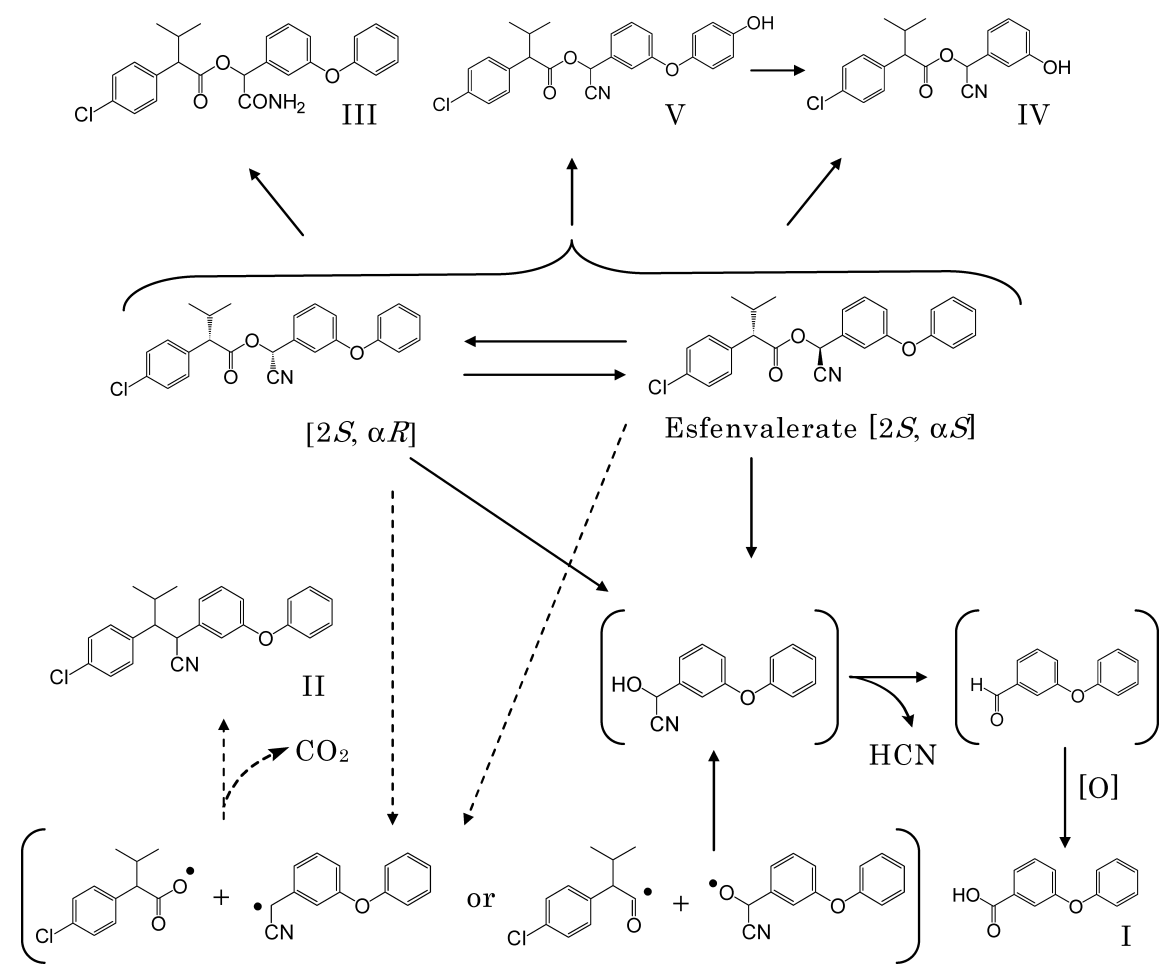

Fig. 1. Proposed degradation pathways of esfenvalerate in water-sediment systems under illumination. Solid line; dark condition, dotted line; photolysis.

thrin, between water and sediment phases.

To assess the application of our experimental system, we conducted an illuminated water-sediment study of esfenvalerate. Esfenvalerate is the $[2 S, \alpha S]$ isomer of fenvalerate, which is known to undergo photo-induced decarboxylation and ester cleavage in water under natural sunlight. ${ }^{10)}$ Due to its high adsorption to sediment, the concentration in a water column rapidly decreased after application to outdoor microcosms but no detailed information on its degradation profiles was available ${ }^{11,12)}$; therefore, we also examined both the contribution of photochemical processes and the effect of surfactant included in the formulation on its distribution and degradation in the illuminated water-sediment system.

\section{Materials and Methods}

\section{Chemicals}

Esfenvalerate uniformly labeled with ${ }^{14} \mathrm{C}$ at the phenoxyphenyl ring was synthesized in our laboratory. ${ }^{13)}$ The specific activity and radiochemical purity was $8.7 \mathrm{MBq} / \mathrm{mg}$ and $98.5 \%$, respectively. 3-Phenoxybenzoic acid (I) and Tween $^{\circledR} 85$ were purchased from Tokyo Kasei Kogyo Co., Ltd. (Tokyo, Japan) and MP Biomedicals, Inc. (Eschwege, Germany), respectively, and used without further purification. Decarboxylated (II), amide (III), desphenyl (IV) and 4'-hydroxylated (V) derivatives of esfenvalerate as racemic mixtures (Fig. 1) were synthesized as potential degradates in our laboratory according to the reported methods ${ }^{14-16)}$ as well as non-labeled esfenvalerate. The chemical purity of each standard was determined to be $>95 \%$ by high-performance liquid chromatography. The blank formulation of emulsifiable concentrate (EC) of commercially supplied esfenvalerate (SumiAlpha ${ }^{\circledR}$ 5EC) was prepared in our Agricultural Chemicals Research Laboratory. To prepare ${ }^{14} \mathrm{C}$-formulation, $0.1 \mathrm{ml}$ of the blank formulation was diluted to $20 \mathrm{ml}$ with distilled water. A thin film of ${ }^{14} \mathrm{C}$-esfenvalerate $(19.8 \mu \mathrm{g})$ was prepared in a 20 $\mathrm{ml}$ volumetric flask by evaporating solvent under a gentle stream of nitrogen gas. An $80-\mu$ l aliquot of the diluted blank formulation was added to the volumetric flask and then the volume was adjusted to $20 \mathrm{ml}$ with distilled water. The flask was shaken well to establish a uniform solution corresponding to the $5 \%$ EC formulation.

\section{Radioassay}

Radioactivity in the water layer, organic extracts of water and sediment and trapping media was individually measured by liquid scintillation counting (LSC) with a Packard model 2000CA liquid scintillation counter equipped with an automatic external standard in low potassium glass vials, using 10 $\mathrm{ml}$ of Packard Emulsifier Scintillator Plus ${ }^{\mathrm{TM}}$. The unextractable sediment residue was powdered after drying at room temperature and its portion was subjected to combustion analysis using a Packard model 307 sample oxidizer with a ${ }^{14} \mathrm{C}$ recovery of $>95 \%$. Details of these radioassays have been previously reported. ${ }^{17)}$ 


\section{Chromatography}

Extracts of water and sediment were individually analyzed by reverse-phase high-performance liquid chromatography (HPLC). A Hitachi L-2130 liquid chromatograph equipped with a Sumipax ODS A-212 column $(5 \mu \mathrm{m}, 6-\mathrm{mm}$ i.d. $\times 15$ cm, Sumika Analytical Service, Ltd., Osaka, Japan) was operated at a flow rate of $1 \mathrm{ml} \mathrm{min}{ }^{-1}$ using mobile phase stepwise changing as follows: $0 \mathrm{~min}$, 0:5:95 (methanol:acetonitrile: $0.01 \%$ acetic acid); $0-15 \mathrm{~min}$, linear, $10: 30: 60$ at $15 \mathrm{~min}$; $15-25 \mathrm{~min}$, linear, $40: 40: 20$ at $25 \mathrm{~min} ; 25-35 \mathrm{~min}$, isocratic, $40: 40: 20$ at $35 \mathrm{~min} ; 35-45 \mathrm{~min}$, linear, 50:50:0 at $45 \mathrm{~min}$; 45-46 min, linear, 0:5:95 at $46 \mathrm{~min} ; 46-60 \mathrm{~min}$, isocratic, 0:5:95 at $60 \mathrm{~min}$. The isomeric contents of esfenvalerate and its enantiomers were determined by chiral HPLC analysis. A Hitachi L-6200 pump equipped with a chiral column SUMIPAX OA-2000 (5 $\mu \mathrm{m}, 4-\mathrm{mm}$ i.d. $\times 25 \mathrm{~cm}$, Sumika Chemical Analysis Service, Ltd., Osaka, Japan) was operated isocratically using $n$-hexane/1,2-dichloroethane/isopropyl alcohol $=500 / 30 / 1(\mathrm{v} / \mathrm{v} / \mathrm{v})$ as a mobile phase at a flow rate of $1 \mathrm{ml} \mathrm{min}{ }^{-1}$ with the following retention times: [2S, $\left.\alpha R\right]$, $20.1 \mathrm{~min} ;[2 R, \alpha S], 21.3 \mathrm{~min} ;[2 S, \alpha S$ ] (esfenvalerate), 23.7 min; $[2 R, \alpha \mathrm{R}], 24.2 \mathrm{~min}$. The radioactivity of the column effluent was monitored with a Flow Scintillation Analyzer 610TR (PerkinElmer) equipped with a 500- $\mu$ l liquid cell using Ultima-Flo AP $^{\circledR}$ (PerkinElmer) as a scintillator. Each ${ }^{14} \mathrm{C}$ peak was identified in HPLC co-chromatography by comparing its retention time with those of non-radiolabeled authentic standards detected by the UV detector at $254 \mathrm{~nm}$.

To further confirm the chemical identity of each degradate, thin-layer chromatography (TLC) was conducted using precoated silica gel $60 \mathrm{~F}_{254}$ thin-layer chromatoplates $(20 \times 20 \mathrm{~cm}$, $0.25-\mathrm{mm}$ layer thickness, E. Merck) with the solvent systems of A; $n$-hexane/acetone (4/1, v/v) and/or B; $n$-hexane/diethyl ether/acetic acid $(75 / 25 / 1, \mathrm{v} / \mathrm{v} / \mathrm{v})$. The latter solvent system was also used to analyze the isomeric contents of some samples. Autoradiograms were prepared by exposing a TLC plate to a BAS-III suji imaging plate (Fuji Photo Film Co., Ltd.) for several days, and the radioactivity in each spot and diffuse region was quantified using a Typhoon 9200 Variable Mode Imager (Amersham Biosciences). Non-radiolabeled reference standards were detected by ultraviolet light at $254 \mathrm{~nm}$. Since III and V could not be separated by reversed phase HPLC, these degradation products were identified by TLC. Typical HPLC retention times $\left(R_{t}\right)$ in the reverse-phase and TLC $R_{f}$ values of esfenvalerate and its potential degradates are listed in Table 1.

\section{Metabolism Studies}

Natural sediments with associated surface water collected from two Japanese ponds in Okayama and Shiga Prefectures were passed through $2-\mathrm{mm}$ and $250-\mu \mathrm{m}$ sieves prior to use, respectively, to remove stones and plant debris. Their physical and chemical properties are listed in Table 2. Each sediment equivalent to $8 \mathrm{~g}$ (Okayama pond) or $20 \mathrm{~g}$ (Shiga pond) on a
Table 1. Chromatographic properties of esfenvalerate and its potential metabolites

\begin{tabular}{|c|c|c|c|}
\hline \multirow{2}{*}{ Compound $^{a)}$} & \multirow{2}{*}{$\begin{array}{c}\text { HPLC } \\
R_{\mathrm{t}}(\min )^{b)}\end{array}$} & \multicolumn{2}{|c|}{$\operatorname{TLC} R_{\mathrm{f}}{ }^{c)}$} \\
\hline & & $\mathrm{A} \times 2$ & $\mathrm{~B} \times 3$ \\
\hline Esfenvalerate & 47 & 0.54 & 0.70 \\
\hline$[2 S, \alpha R]$ isomer & 47 & 0.54 & 0.67 \\
\hline I & 30 & 0.15 & 0.35 \\
\hline II & 45 & 0.57 & 0.69 \\
\hline III & 39 & 0.14 & 0.08 \\
\hline IV & 35 & 0.24 & 0.29 \\
\hline V & 39 & 0.20 & 0.22 \\
\hline
\end{tabular}

a) Corresponding structures are shown in Fig. $1 .{ }^{b)}$ Typical HPLC retention time. ${ }^{c)}$ A, $n$-hexane/acetone (4/1, v/v); B, n-hexane/diethyl ether/acetic acid $(75 / 25 / 1, \mathrm{v} / \mathrm{v} / \mathrm{v})$. " $\times$ " means repeated development with each solvent system.

dry-weight basis was added to a two-necked cylindrical Pyrex glass vessel (4.5-cm diameter) to a depth of $2-2.5 \mathrm{~cm}$. The associated water was added to the vessel to a depth of $6 \mathrm{~cm}$ above the sediment in accordance with the BBA guideline. ${ }^{18)}$ The water-sediment system was then pre-incubated in darkness at $20 \pm 1^{\circ} \mathrm{C}$ for two weeks to one month.

After the pre-incubation, $0.1 \mathrm{ml}$ of acetonitrile $(0.1 \%$ in a final volume) solution of ${ }^{14} \mathrm{C}$-esfenvalerate or $0.8 \mathrm{ml}$ of ${ }^{14} \mathrm{C}$ formulation was dropwise fortified to the water surface in each vessel using a microsyringe or pipet, respectively. The application rate of esfenvalerate to each water-sediment system was conveniently adjusted to $0.8 \mu \mathrm{g} / \mathrm{vessel}$ equivalent to the field application rate of $25 \mathrm{~g}$ a.i / ha by assuming a uniform distribution in the water phase to a depth of $30 \mathrm{~cm} .{ }^{18)}$ Humidified air was passed over the water phase through each vessel in sequence to one gas washing bottle containing $300 \mathrm{ml}$ of

Table 2. Characteristics of Japanese pond sediment and associated water samples

\begin{tabular}{ccc}
\hline \multicolumn{1}{c}{ Location } & Okayama & Shiga \\
\hline Sediment & & \\
Soil texture (\%) & & \\
Sand & 27.4 & 65.9 \\
Silt & 33.7 & 15.0 \\
Clay & 38.9 & 19.1 \\
Soil classification & Light clay & Sandy clay \\
Organic carbon $(\%)$ & 5.3 & 2.7 \\
pH $\left(\mathrm{H}_{2} \mathrm{O}\right)$ & 6.6 & 7.4 \\
Associated water & & \\
Suspended matter $\left(\mathrm{g} / \mathrm{m}^{3}\right)$ & 170 & 140 \\
pH & 7.1 & 8.4 \\
\hline
\end{tabular}


ethylene glycol and the other containing $350 \mathrm{ml}$ of $0.5 \mathrm{M}$ $\mathrm{NaOH}$ solution to trap volatile ${ }^{14} \mathrm{C}$. The water-sediment system was placed in an incubator and kept at $20 \pm 1^{\circ} \mathrm{C}$ in darkness. In order to maintain homogeneity in the water layer, the whole apparatus was set on an orbital shaker (MK-2000, Yamato Scientific) at $20 \mathrm{rpm}$ to moderately mix the water phase during the study.

In the case of illuminated water-sediment systems, each glass vessel was irradiated only from the top side using a 2 kW Xenon arc lamp (UXL-25SC Xenon lamp, Usio, Tokyo, Japan) through a Pyrex glass plate (4 mm thickness) to remove UV light with wavelengths below $290 \mathrm{~nm}$, as previously reported. ${ }^{4)}$ Light intensity was kept almost constant throughout the experiment with irradiance at 300 to $400 \mathrm{~nm}$ of 0.672 $\mathrm{MJ} / \mathrm{m}^{2} /$ day on average. Illumination was continued for $8 \mathrm{hr} /$ day during the experiment, which was equivalent to the daily irradiance of natural sunlight in Tokyo $\left(35^{\circ} \mathrm{N}\right.$, April-June). The temperature of the system was kept at $20 \pm 1^{\circ} \mathrm{C}$ by immersing the glass vessels in circulating chilled water in a bath. The surface water, sediment and trapping media were extracted and analyzed by HPLC and/or TLC at appropriate intervals as described previously ${ }^{17}$ ) except for using acetone as an extraction solvent for sediment.

Furthermore, in order to examine the effect of sediment on the photolytic profiles of esfenvarelate, its photodegradation in the natural water overlying the sediment and distilled water was examined at $20 \pm 1^{\circ} \mathrm{C}$ for 7 days using the same apparatus as above but in the absence of sediment. The same application rate thus exceeded the water solubility of $2 \mathrm{ppb}$ at $25^{\circ} \mathrm{C}$. ${ }^{19)}$ Water was sterilized by autoclaving for $20 \mathrm{~min}$ at $1.5 \mathrm{~kg} \mathrm{~cm}^{-2}$ and $120^{\circ} \mathrm{C}$ using an SS-325 autoclave (Tomy Seiko Co., Ltd). In addition to aqueous acetonitrile and $\mathrm{EC}$ formulation, the aqueous suspension of esfenvalerate was prepared using Tween 85 since its homogeneous aqueous solution is considered difficult to prepare due to its extremely low water solubility. To $200 \mathrm{ml}$ of distilled water, ${ }^{14} \mathrm{C}$-esfenvalerate $(1.7 \mu \mathrm{g})$ in acetonitrile $(2 \mathrm{ml} ; 1 \%)$ or the $5 \%$ EC formulation $(1.6 \mathrm{ml})$ was added, followed by a mechanical shaking for $1 \mathrm{hr}$ in darkness. The suspension of ${ }^{14} \mathrm{C}$-esfenvalerate $(1.7 \mu \mathrm{g})$ in the presence of 50-fold amount (w/w) of Tween 85 was prepared similarly to above. After confirmation of the applied radioactivity in each suspension by LSC, $95 \mathrm{ml}$ of each solution was irradiated under the same illuminated conditions with a portion periodically subjected to LSC and HPLC co-chromatographic analyses. As controls, each aqueous solution was similarly incubated in darkness.

\section{Results and Discussion}

\section{Photodegradation in water}

An aqueous solution of ${ }^{14} \mathrm{C}$-esfenvalerate could be prepared at an approximate nominal concentration in any water tested using the formulation and co-solvent of 50 -fold Tween 85 or $1 \%$ acetonitrile. Immediate analysis of time- 0 samples showed neither the significant adsorption of esfenvalerate onto a glass surface nor its degradation during the preparation of solutions; however, in every preparation, its significant adsorption to a glass surface was observed as previously reported for fenvalerate ${ }^{20)}$ and there seems to be no clear trend of adsorption among each preparation (Table 3). The adsorption coefficient $\left(K_{\mathrm{w}}\right)$ of esfenvalerate 7 days after application was conveniently calculated using the following equation based on the solution volume of $c a .95 \mathrm{ml}$ and the internal glass surface area of $c a .100 \mathrm{~cm}^{2}$.

$$
K_{\mathrm{w}}=\frac{\text { Concentration on glass wall }\left(\mu \mathrm{g} / \mathrm{cm}^{2}\right)}{\text { Aqueous concentration }\left(\mu \mathrm{g} / \mathrm{cm}^{3}\right)}
$$

$K_{\mathrm{w}}$ values were $0.7-1.5$ (dark) and $0.3-2.2$ (light), as listed in Table 4, and were similar to those reported for other pyrethroids $(0.82-0.94 \mathrm{~cm}) .{ }^{21)}$ Epimerization of esfenvalerate to the $[2 S, \alpha R]$ isomer was observed both in water and adsorbed phases. The isometric ratio of the $[2 S, \alpha R]$ isomer to esfenvalerate was mostly around 1 after 7 days, irrespective of illumination. Similar epimerization at the $\alpha$-cyanobenzyl carbon has been reported for deltamethrin and is considered to be a dark reaction via proton exchange with solvents. ${ }^{22)}$ More epimerization in an alkaline condition than neutral has been reported with the corresponding ratios of 17/76 $(\mathrm{pH} \mathrm{7)}$ and 48/48 ( $\mathrm{pH}$ 9) after 7 days in darkness (unpublished), which can explain the lower epimerization observed in the EC formulation of distilled water ( $\mathrm{pH} 7.1$ ). Inspective of illumination, I was the main degradate and was likely to be formed via ester cleavage followed by successive release of hydrogen cyanide from the cyanohydrin and oxidation of the resulting 3-phenoxybenzaldehyde, ${ }^{10,15)}$ as shown in Fig. 1. Sterilization greatly reduced the formation of I in the dark control, indicating in part the involvement of microbial hydrolysis of esfenvalerate. ${ }^{23)}$ The amounts of I in the dark control of the reported photodegradation of fenvalerate ${ }^{10)}$ are similar to those in the sterile condition of this study, which supports the microbial processes.

Under illumination, the decarboxylated derivative (II) was specifically detected in every solution and on glass surfaces at $0.9-4.1 \%$ and $0.7-2.0 \%$ of the applied ${ }^{14} \mathrm{C}$ after 7 days, respectively. The small differences in the amount of II among each solution mean the poor formation of a solvent cage by Tween 85 and surfactant included in the EC formulation, which is considered to stabilize photochemically generated radical pairs. ${ }^{3)}$ Illumination greatly enhanced the degradation of esfenvalerate in Shiga pond water as evidenced by the increased amounts of degradates, for example from 7.0 to $22.6 \%$ (Tween 85 ) and 18.2 to $24.0 \%$ (1\% acetonitrile) after 7 days, together with the more formation of I. Similar enhancement was observed under sterile conditions using the EC formulation, while the effect of illumination was insignificant in non-sterile samples (Table 3). This indicates the importance of microbial processes in the real aquatic environment but with its extent being reduced by the presence of Tween 85 and $1 \%$ acetonitrile in the present study. II is considered to be 


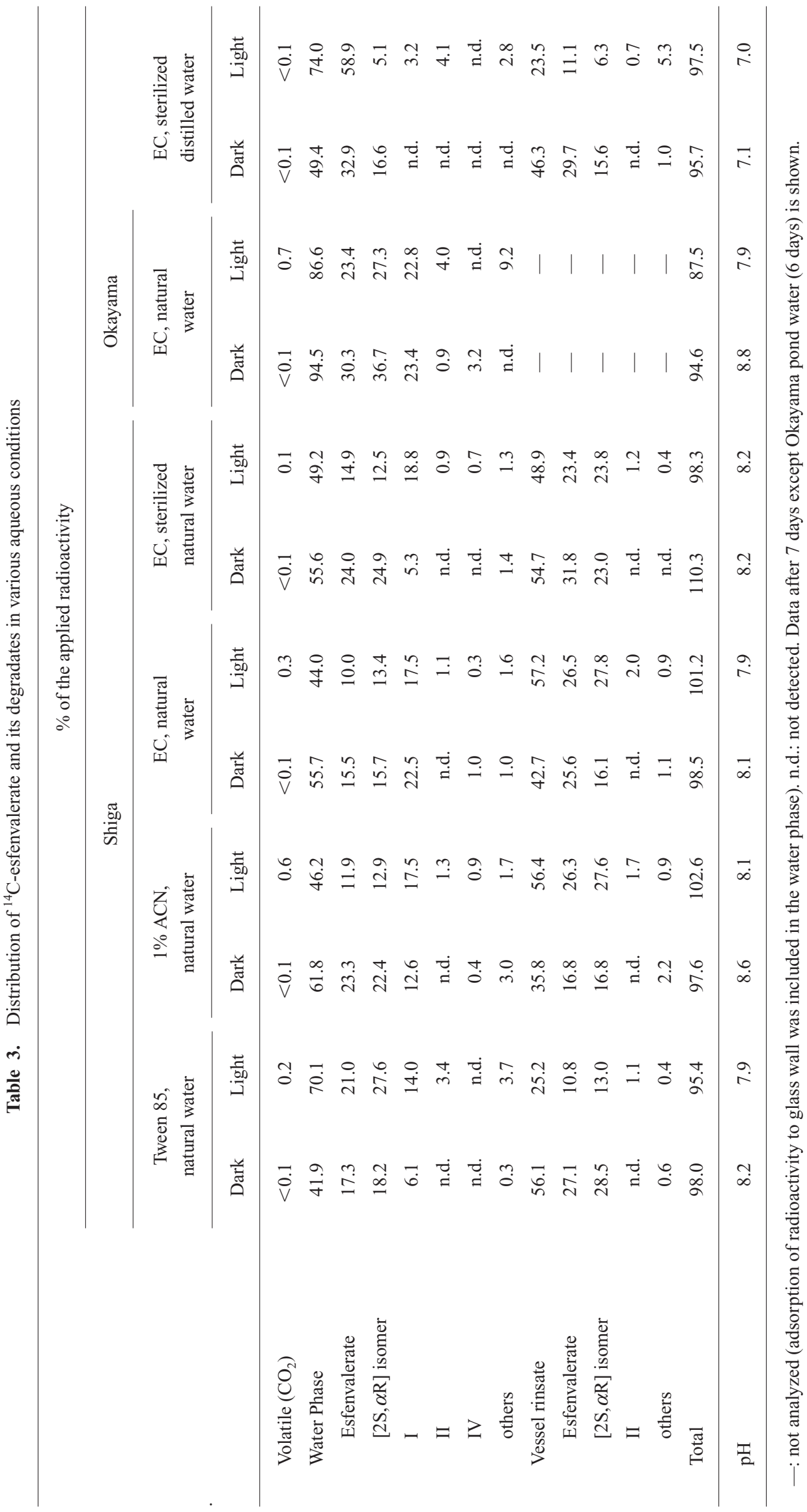


Table 4. Adsorption affinity of esfenvalerate on a glass wall under various conditions

\begin{tabular}{lllll}
\hline \multirow{2}{*}{$\begin{array}{c}\text { Aqueous } \\
\text { solution }\end{array}$} & Co-solvent & Condition & \multicolumn{2}{c}{$K_{\mathrm{w}}(\mathrm{cm})$} \\
\cline { 4 - 5 } & & & Dark & Light \\
\hline \multirow{2}{*}{ Natural (Shiga) } & Tween 85 & Non-sterile & 1.5 & 0.5 \\
& $1 \%$ ACN & Non-sterile & 0.7 & 2.1 \\
& EC & Non-sterile & 1.3 & 2.2 \\
& & Sterile & 1.1 & 1.6 \\
Distilled & EC & Sterile & 0.9 & 0.3 \\
\hline
\end{tabular}

formed via recombination of radical pairs through the release of $\mathrm{CO}_{2}$, as shown in Fig. 1 and therefore, this increase of I may originate from either photo-induced ester cleavage, the formation of cyanhydrin as an intermediate to I via cleavage of the benzyl carbon-oxygen bond or some indirect photolysis mechanism, as reported for solid-phase photodegradation. ${ }^{24)}$ Finally, the mineralization of esfenvalerate to carbon dioxide was slightly accelerated by illumination; therefore, the effects of co-solvent or formulation on the profiles of adsorption and photodegradation were not significant, while the origin of water more affected the distribution, similarly to the dark control. The insignificant effect of Tween 85 may originate from its dilute concentration below the critical micelle concentration $\left.(23 \mathrm{ppm}){ }^{25}\right)$

\section{Degradation in the water-sediment system}

In the Shiga pond water-sediment system, the redox potential mostly ranged from 180 to $223 \mathrm{mV}$ and from -114 to -210 $\mathrm{mV}$ for the water and sediment phases, respectively, and was

Table 5. Distribution of ${ }^{14} \mathrm{C}$-esfenvalerate and its degradates in Shiga water-sediment system spiked with $0.1 \%$ aqueous acetonitrile solution

$\%$ of the applied radioactivity

\begin{tabular}{|c|c|c|c|c|c|c|c|c|}
\hline & \multicolumn{4}{|c|}{ Dark } & \multicolumn{4}{|c|}{ Light } \\
\hline & $0 \mathrm{~d}$ & $1 \mathrm{~d}$ & $3 \mathrm{~d}$ & $7 d$ & $0 \mathrm{~d}$ & $1 \mathrm{~d}$ & $3 \mathrm{~d}$ & $7 d$ \\
\hline Volatile $\left(\mathrm{CO}_{2}\right)$ & - & - & 13.2 & 21.8 & - & 0.4 & 2.5 & 4.8 \\
\hline Water phase & 70.4 & 43.8 & 30.6 & 23.7 & 70.5 & 5.0 & 10.1 & 20.7 \\
\hline Esfenvalerate* & 69.7 & 33.0 & 22.8 & 11.5 & 69.8 & 3.3 & 3.9 & 13.7 \\
\hline I & n.d. & 1.8 & n.d. & 0.7 & n.d. & 1.7 & 6.3 & 6.7 \\
\hline IV & n.d. & 2.4 & 1.8 & 3.9 & n.d. & n.d. & n.d. & n.d. \\
\hline $\mathrm{V}$ & n.d. & 1.2 & 4.2 & 3.8 & n.d. & n.d. & n.d. & n.d. \\
\hline others & 0.4 & 5.4 & 1.8 & 3.8 & 0.7 & n.d. & n.d. & 2.0 \\
\hline Sediment phase & 22.4 & 48.9 & 47.5 & 42.7 & 23.8 & 88.3 & 78.3 & 68.1 \\
\hline Extract & 22.4 & 44.2 & 39.7 & 32.6 & 22.4 & 85.1 & 73.0 & 60.9 \\
\hline Esfenvalerate* & 22.4 & 44.2 & 35.4 & 21.9 & 22.4 & 83.9 & 69.9 & 55.6 \\
\hline I & n.d. & n.d. & n.d. & n.d. & n.d. & n.d. & 0.4 & 1.6 \\
\hline II & n.d. & n.d. & n.d. & n.d. & n.d. & 1.1 & 1.5 & 1.9 \\
\hline IV & n.d. & n.d. & n.d. & 3.5 & n.d. & n.d. & n.d. & n.d. \\
\hline $\mathrm{V}$ & n.d. & n.d. & 3.6 & 7.2 & n.d. & n.d. & n.d. & n.d. \\
\hline others & n.d. & n.d. & 0.7 & n.d. & n.d. & n.d. & 1.2 & 1.7 \\
\hline Bound residues & 1.4 & 4.7 & 7.8 & 10.5 & 1.4 & 3.2 & 5.3 & 7.2 \\
\hline Total & 94.2 & 92.7 & 91.3 & 88.2 & 94.3 & 93.7 & 90.9 & 93.6 \\
\hline \multicolumn{9}{|l|}{ Water phase } \\
\hline $\mathrm{pH}$ & 8.0 & 8.0 & 8.0 & 8.2 & 8.0 & 7.7 & 8.1 & 7.8 \\
\hline ORP (mV) & 180 & 190 & 194 & 192 & 180 & 192 & 200 & 223 \\
\hline \multicolumn{9}{|l|}{ Sediment phase } \\
\hline $\mathrm{pH}$ & 7.1 & 7.2 & 7.2 & 7.6 & 7.1 & 7.2 & 7.0 & 7.2 \\
\hline ORP (mV) & -114 & -180 & -150 & -190 & -114 & -179 & -210 & -47 \\
\hline
\end{tabular}

—: not analyzed. n.d.: not detected. *: including $[2 S, \alpha R]$ isomer. 
Table 6. Distribution of ${ }^{14} \mathrm{C}$-esfenvalerate and its degradates in Shiga water-sediment system spiked with EC formulation

\begin{tabular}{|c|c|c|c|c|c|c|c|c|}
\hline & \multicolumn{8}{|c|}{$\%$ of the applied radioactivity } \\
\hline & \multicolumn{4}{|c|}{ Dark } & \multicolumn{4}{|c|}{ Light } \\
\hline & $0 \mathrm{~d}$ & $1 \mathrm{~d}$ & $3 \mathrm{~d}$ & $7 \mathrm{~d}$ & $0 \mathrm{~d}$ & $1 \mathrm{~d}$ & $3 \mathrm{~d}$ & $7 \mathrm{~d}$ \\
\hline Volatile $\left(\mathrm{CO}_{2}\right)$ & - & - & 3.9 & 12.9 & - & 0.3 & 2.9 & 9.8 \\
\hline Water phase & 99.6 & 32.6 & 27.3 & 11.5 & 99.6 & 9.1 & 10.9 & 6.0 \\
\hline Esfenvalerate* & 98.7 & 29.7 & 22.7 & 5.2 & 98.7 & 5.7 & 4.2 & 3.3 \\
\hline I & n.d. & 1.5 & 1.1 & n.d. & n.d. & 3.4 & 6.7 & 2.7 \\
\hline $\mathrm{V}$ & n.d. & n.d. & 1.7 & 2.4 & n.d. & n.d. & n.d. & n.d. \\
\hline others & 0.8 & 1.2 & 1.8 & 3.9 & 0.8 & n.d. & n.d. & 0.1 \\
\hline Sediment phase & 1.4 & 67.1 & 64.1 & 67.9 & 1.4 & 90.9 & 85.7 & 82.6 \\
\hline Extract & 1.3 & 63.8 & 58.9 & 58.4 & 1.3 & 86.1 & 78.0 & 67.6 \\
\hline Esfenvalerate* & - & 63.8 & 56.5 & 44.9 & - & 84.6 & 74.5 & 60.6 \\
\hline I & - & n.d. & n.d. & n.d. & - & n.d. & n.d. & n.d. \\
\hline $\mathrm{V}$ & - & n.d. & 2.1 & 12.0 & - & 0.4 & 1.1 & 2.8 \\
\hline others & - & n.d. & 0.3 & 0.5 & - & 1.1 & 2.4 & 4.2 \\
\hline Bound residues & 0.1 & 3.0 & 4.7 & 9.7 & 0.1 & 4.8 & 7.6 & 15.0 \\
\hline Total & 101.1 & 99.4 & 94.7 & 91.7 & 101.0 & 100.3 & 99.5 & 98.4 \\
\hline \multicolumn{9}{|l|}{ Water phase } \\
\hline $\mathrm{pH}$ & 7.6 & 7.9 & 8.1 & 8.0 & 7.6 & 8.0 & 7.3 & 8.2 \\
\hline ORP (mV) & 180 & 202 & 185 & 192 & 180 & 198 & 105 & 215 \\
\hline \multicolumn{9}{|l|}{ Sediment phase } \\
\hline $\mathrm{pH}$ & 7.4 & 7.1 & 7.1 & 7.1 & 7.4 & 7.4 & 7.1 & 7.3 \\
\hline ORP (mV) & -123 & -200 & -196 & -153 & -123 & -137 & -209 & -149 \\
\hline
\end{tabular}

—: not analyzed. n.d.: not detected. *: including $[2 S, \alpha R]$ isomer.

not significantly affected by either illumination or application medium. The water column was kept aerobic by continuous air introduction and the bottom sediment was anaerobic. The $\mathrm{pH}$ value in each phase was also kept constant throughout the study and was slightly alkaline in the water column. Although measurements were conducted only for the dark control, the constant but slightly more aerobic condition was observed for the Okayama pond system where the redox potential ranged from 309 to $426 \mathrm{mV}$ and from 17 to $-96 \mathrm{mV}$ for the water and sediment phases, respectively.

The good total recovery of radioactivity was mostly realized, as listed in Tables 5, 6 and 7. More mineralization was observed in the dark control than under illumination for both systems. When esfenvalerate was applied as $0.1 \%$ acetonitrile solution in darkness, ${ }^{14} \mathrm{CO}_{2}$ finally amounted to $21.8 \%$ of the applied ${ }^{14} \mathrm{C}$. More formation of $\mathrm{CO}_{2}$ as compared with the illuminated studies was accounted for by predominantly microbial processes in the presence of sediment. Samsфe-Petersen et $a{ }^{26)}{ }^{26}$ have reported mineralization of less than $5 \%$ in the same period from [phenoxyphenyl- ${ }^{14} \mathrm{C}$ ] esfenvalerate in dark- ness when applied to a Danish pond water-sediment system at 5 and $98 \mathrm{ppb}$. This difference was likely to stem from the lower temperature $\left(15^{\circ} \mathrm{C}\right)$ in their study.

At the initiation of the study using $0.1 \%$ acetonitrile solution, $22.4 \%$ of the applied ${ }^{14} \mathrm{C}$ was immediately transferred to the Shiga sediment, while insignificant ${ }^{14} \mathrm{C}$ was found when the EC formulation was applied to both sediments. This difference is likely to originate from the existence of aggregates or micelles solubilizing esfenvalerate in the EC formulation but its effect rapidly disappeared, possibly by the adsorption of surfactants to the sediment surface. Since the surfactants are known to form admicelles and hemimicelles on solid surfaces, such as sediment, which facilitate adsorption of a chemical, ${ }^{27)}$ more partition of ${ }^{14} \mathrm{C}$ to sediments with application of the EC formulation in darkness was likely to reflect this adsorption of surfactants. This surfactant effect has not been observed for the EC formulation of five pesticides applied to the English water-sediment system ${ }^{9)}$ and this inconsistency may originate from differences in a surfactant composition of the formulation. Esfenvalerate in the water phase 
Table 7. Distribution of ${ }^{14} \mathrm{C}$-esfenvalerate and its degradates in Okayama water-sediment system spiked with EC formulation

\begin{tabular}{|c|c|c|c|c|c|c|c|c|}
\hline & \multicolumn{8}{|c|}{$\%$ of the applied radioactivity } \\
\hline & \multicolumn{8}{|c|}{ Days after application } \\
\hline & \multicolumn{4}{|c|}{ Dark } & \multicolumn{4}{|c|}{ Light } \\
\hline & $0 \mathrm{~d}$ & $1 \mathrm{~d}$ & $7 \mathrm{~d}$ & $15 \mathrm{~d}$ & $0 \mathrm{~d}$ & $1 \mathrm{~d}$ & $7 \mathrm{~d}$ & $15 \mathrm{~d}$ \\
\hline Volatile $\left(\mathrm{CO}_{2}\right)$ & - & $<0.1$ & 4.2 & 9.2 & - & $<0.1$ & 3.2 & 4.1 \\
\hline Water phase & 103.0 & 43.1 & 15.9 & 11.3 & 103.0 & 35.3 & 18.7 & 15.8 \\
\hline Esfenvalerate* & 103.0 & 40.7 & 13.3 & 11.3 & 103.0 & 32.8 & 7.0 & n.d. \\
\hline I & n.d. & 2.3 & 2.6 & n.d. & n.d. & 2.5 & 10.8 & 13.0 \\
\hline others & n.d. & n.d. & n.d. & n.d. & n.d. & n.d. & 0.9 & 2.8 \\
\hline Sediment phase & $<0.1$ & 54.7 & 77.3 & 80.5 & $<0.1$ & 60.7 & 79.9 & 81.5 \\
\hline Extract & - & 52.6 & 67.8 & 65.2 & - & 58.2 & 64.6 & 46.6 \\
\hline Esfenvalerate* & - & 52.6 & 63.8 & 57.1 & - & 58.2 & 62.4 & 40.7 \\
\hline I & - & n.d. & 1.5 & n.d. & - & n.d. & 2.2 & 3.3 \\
\hline III & - & n.d. & 0.5 & 0.4 & - & n.d. & n.d. & 0.8 \\
\hline IV & - & n.d. & n.d. & 1.6 & - & n.d. & n.d. & n.d. \\
\hline $\mathrm{V}$ & - & n.d. & 1.9 & 2.4 & - & n.d. & n.d. & 1.8 \\
\hline others & - & n.d. & n.d. & 0.8 & - & n.d. & n.d. & n.d. \\
\hline Bound residues & $<0.1$ & 2.1 & 9.5 & 15.2 & $<0.1$ & 2.5 & 15.3 & 34.8 \\
\hline Vessel rinsate & 0.2 & 0.1 & 0.1 & 0.2 & 0.2 & 0.1 & 0.1 & 0.1 \\
\hline Total & 103.2 & 97.9 & 97.5 & 101.2 & 103.2 & 99.4 & 97.3 & 87.5 \\
\hline
\end{tabular}

—: not analyzed. n.d.: not detected. *: including $[2 S, \alpha R]$ isomer.

dissipated with a half-life of around 1 day at least in part due to its rapid partition to sediment. The slightly faster dissipation was observed under illumination with its residues decreasing to $3.3-13.7 \%$ of the applied ${ }^{14} \mathrm{C}$ after 7 days. The probable turbulence of the overlying water under illumination may account for the accelerated partition of esfenvalerate from water to sediment. Very similar rapid dissipation of esfenvalerate has been reported with the application of its EC formulation to littoral enclosures in a 2-ha pond and the residues of depth-integrated water columns decreased to less than $10 \%$ of the application dose within 1 day. ${ }^{12)}$

Since kinetic analysis either by a compartment model or of dissipation in the water phase failed to estimate the dissipation rates, simple first-order kinetics was applied to the total decline of esfenvalerate and its $[2 S, \alpha R]$ isomer in the watersediment system. Dissipation half-lives, mostly with correlation coefficients of $>0.9$, were estimated to be $4.7 \mathrm{~d}$ (dark) and $16.1 \mathrm{~d}$ (light) for the Shiga pond water-sediment system spiked with $0.1 \%$ aqueous acetonitrile solution. Spiking of the EC formulation resulted in similar values, $7.4 \mathrm{~d}$ (dark) and $13.9 \mathrm{~d}$ (light), while longer half-lives were estimated for the Okayama pond water-sediment system, $25.5 \mathrm{~d}$ (dark) and 11.9 d (light). A greater amount of esfenvalerate with less partition to the sediment seemed to increase photolytic contribution in water-sediment systems spiked with the EC formulation.

Irrespective of illumination, esfenvalerate in the water phase underwent epimerization to the $[2 S, \alpha R]$ isomer whose ratio to esfenvalerate became approximately 1 after 7 days, as demonstrated by chiral HPLC analysis (Table 8). The main degradate in water was I, amounting to $0.7-2.6 \%$ in darkness and $1.7-13.0 \%$ under illumination. In the dark controls of the Shiga water-sediment system, desphenyl (IV) and 4'-OH (V) derivatives were additionally detected. Little detailed information on the route of degradation in a water-sediment system is available, but ester cleavage has been reported to be one of the main routes for permethrin, alpha-cypermethrin, betacyfluthrin, lambda-cyhalothrin and esfenvalerate. ${ }^{3)}$ Hydroxylation at the $4^{\prime}$-position, desphenylation and epimerization at the $\alpha$-cyanobenzyl carbon of the 3-phenoxybenzyl moiety were also reported for fenvalerate, lambda-cyhalothrin and deltamethrin, respectively. ${ }^{3,23)}$ In contrast to the aqueous photodegradation study, II could not be detected in the water layer of two water-sediment systems. More partition of esfenvalerate to the sediment observed under illumination causes less aqueous concentration for photodegradation, which in part accounts for the reduced formation of II. Furthermore, dissolved humic substances in natural water are considered to disturb the formation of a solvent cage. At the same time, 
Table 8. Amounts of ${ }^{14} \mathrm{C}$-esfenvalerate and its $[2 S, \alpha R]$ isomer in each water-sediment system after 7 days

\begin{tabular}{|c|c|c|c|c|c|c|}
\hline & \multicolumn{6}{|c|}{$\%$ of the applied radioactivity } \\
\hline & \multicolumn{2}{|c|}{ Okayama (EC) } & \multicolumn{2}{|c|}{ Shiga (EC) } & \multicolumn{2}{|c|}{ Shiga (ACN) } \\
\hline & Dark & Light & Dark & Light & Dark & Light \\
\hline \multicolumn{7}{|l|}{ Water } \\
\hline Esfenvalerate & 7.0 & 3.0 & 2.5 & 1.7 & 6.2 & 6.8 \\
\hline$[2 S, \alpha R]$ Isomer & 6.3 & 3.9 & 2.7 & 1.6 & 5.3 & 6.9 \\
\hline$(\text { ratio })^{*}$ & $(1.1)$ & $(0.8)$ & $(0.9)$ & $(1.1)$ & $(1.2)$ & $(1.0)$ \\
\hline \multicolumn{7}{|l|}{ Sediment } \\
\hline Esfenvalerate & 44.0 & 40.2 & 26.3 & 27.5 & 15.3 & 21.1 \\
\hline$[2 S, \alpha R]$ Isomer & 19.8 & 22.3 & 18.5 & 33.0 & 6.6 & 34.6 \\
\hline$($ ratio)* & $(2.2)$ & $(1.8)$ & $(1.4)$ & $(0.8)$ & $(2.3)$ & $(0.6)$ \\
\hline
\end{tabular}

*: isomeric ratio of esfenvalerate to $[2 S, \alpha R]$ isomer.

they would act as a hydrogen donor for the generated radical to form cyanhydrin, which is finally transformed to I either abiotically or microbially. Photo-induced reactions such as cis-trans isomerization in deltamethrin,, ${ }^{6}$ thiono-thiolo rearrangement of fenitrothion ${ }^{28)}$ and desulferation of fipronil ${ }^{29)}$ have been reported in outdoor microcosm studies but their contribution to the surface water layer is limited, with minimum amounts of photoproducts being formed ${ }^{3)}$; therefore, by considering the result in this study, significant formation of II as a natural aquatic body is considered less likely.

In the illuminated sediment phase, markedly fewer degradates were detected as compared with the dark control. Small amounts of II, III and V $(<3 \%)$ were sporadically detected. In contrast, IV and $\mathrm{V}$ were formed in darkness, the latter of which amounted to $7.2-12.0 \%$ of the applied ${ }^{14} \mathrm{C}$ after 7 days, possibly via microbial hydroxylation and desphenylation, as reported in aerobic soil metabolism. ${ }^{23)}$ The amount of bound residues gradually increased to $9.5-10.5 \%$ and $7.2-15.3 \%$ of the applied ${ }^{14} \mathrm{C}$ in darkness and under illumination, respectively, after 7 days. Slightly more bound formation under illumination may stem from more degradation products. Chiral HPLC analysis has shown that the isomeric ratio of esfenvalerate to $[2 S, \alpha R]$ isomer was 1.4 to 2.3 in the dark control, as listed in Table 8 . The different isomeric ratios in sediments from those around unity in the water phase may be accounted for either by slower epimerization than the partition to sediment or faster epimerization under alkaline conditions (unpublished). These mechanisms mostly elucidate higher isomeric ratios in the sediments and a lower ratio in the formulation-spiked Shiga system with a more alkaline water phase than in the Okayama system, but the opposite trends in the illuminated Shiga systems could not be explained.

Based on these results, our water-sediment system could mostly simulate the partition and degradation profiles observed for pyrethroids, including esfenvalerate. The effect of formulation was found not to be significant on these profiles but alteration would occur most likely with illumination of the system simulating the real environment.

\section{References}

1) Society of Environmental Toxicology and Chemistry. 1995. Procedures for Assessing the Environmental Fate and Ecotoxicity of Pesticides, Section 8.2. SETAC Europe. Brussels, Belgium.

2) European Commission. 2002. Working document, Guidance Document on Aquatic Ecotoxicology Sanco/3268/2001.rev.4. European Commission. Brussels, Belgium, pp. 1-62.

3) T. Katagi: Rev. Environ. Contam. Toxicol. 187, 133-251 (2006).

4) R. Kodaka, T. Sugano and T. Katagi: Environ. Toxicol. Chem. 25, 310-316 (2006).

5) I. R. Hill, J. L. Shaw and S. J. Maund: "Freshwater field tests for hazard assessments of chemicals," ed. by I. R. Hill, F. Heimbach, P. Leeuwangh and P. Matthiessen, Lewis Publishers, Boca Raton, Chap. 15, pp. 249-271, 1994.

6) K. M. Erstfeld: Chemosphere 39, 1737-1769 (1999).

7) D. C. G. Muir, G. P. Rawn and N. P. Grift: J. Agric. Food Chem. 33, 603-609 (1985).

8) R. J. Maguire, J. H. Carey, J. H. Hart, R. J. Tkacz and H. Lee: J. Agric. Food Chem. 37, 1153-1159 (1989).

9) R. H. Bromilow, A. A. Evans and P. H. Nicholls: Pest Manag. Sci. 59, 238-244 (2003).

10) N. Mikami, N. Takahashi, K. Hayashi and J. Miyamoto: J. Pestic. Sci. 5, 225-236 (1980).

11) L. Petersen, K. Gustavson, T. Madsen, B. Mogensen, P. Lassen, K. Skjernov, K. Christoffersen and E Jorgensen: Environ. Toxicol. Chem. 20, 1570-1578 (2001).

12) L. J. Heinis and M. L. Knuth: Environ. Tox. Chem. 11, 11-25 (1992).

13) H. Kanamaru, T. Kamada, I. Nakatsuka, Z. Mori, T. Okamura and I. Yoshitake: J. Labelled Compd. Radiopharm. 18, 12831293 (1981)

14) H. Ohkawa, K. Nambu, H. Inui and J. Miyamoto: J. Pestic. Sci. 3, 129-141 (1978). 
15) R. Holmstead, D. Fullmer and L. Ruzo: J. Agric. Food Chem. 26, 954-959 (1978).

16) T. Katagi: J. Agric. Food Chem. 39, 1351-1356 (1991).

17) R. Kodaka, T. Sugano, T. Katagi and Y. Takimoto: J. Pestic. Sci. 27, 235-241 (2002).

18) Federal Biological Institute for Agriculture and Forestry (Biologische Bundesanstalt, BBA). 1990. Guidelines for the examination of plant protectants in the registration process, Part IV, Section 5-1. BBA. Braunschweig, Germany.

19) X. Xia and R. Wang: Environ. Toxicol. Chem. 27, 119-125 (2008).

20) K. Day and N. K. Kaushik: Aquatic Tox. 10, 131-142 (1987).

21) J. L. Zhou, S. Rowland and R. F. C. Mantoura: Wat. Res. 4, 1023-1031 (1995).
22) L. O. Ruzo, R. L. Holmstead and J. E. Casida: J. Agric. Food Chem. 25, 1385-1394 (1977).

23) S. Sakata, N. Mikami and H. Yamada: J. Pestic. Sci. 17, 169180 (1992).

24) T. Katagi: J. Agric. Food Chem. 41, 2178-2183 (1993).

25) L. S. C. Wan and P. F. S. Lee: J. Pharm. Sci. 63, 136-137 (1974).

26) L. Samsфe-Petersen, K. Gustavson, T. Madsen, B. B. Mogensen, P. Lassen, K. Skjernov, K. Christoffersen and E. Jorgensen: Environ. Toxicol. Chem. 20, 1570-1578 (2001).

27) T. Katagi: Rev. Environ. Contam. Toxicol. 194, 71-177 (2008).

28) P. Weinberger, R. Greenhalgh, R. P. Moody and B. Boulton: Environ. Sci. Technol. 16, 470-473 (1982).

29) S. S. Walse, P. L. Pennington, G. I. Scott and J. L. Ferry: J. Environ. Monitor. 6, 58-64 (2004). 